\title{
A JURISPRUDENCIALIZAÇÃO DO DIREITO COMO VIOLAÇÃO ÀS GARANTIAS FUNDAMENTAIS
}

\author{
THE OVERUSE OF THE CASE LAW AS VIOLATION TO THE \\ FUNDAMENTAL GUARANTEES
}

\section{Resumo}

Este trabalho objetiva apresentar críticas constitucionalmente fundadas a respeito da aplicação em massa do mecanismo jurisprudencial, por parte do Estado-juiz, quando da prestação da tutela jurisdicional. Busca-se demonstrar como esta prática pode prejudicar a atuação das partes no desenvolvimento do processo, limitando a incidência de garantias constitucionais fundamentais e, consequentemente, os direitos que estes mecanismos visam proteger. Em seguida, uma análise do papel que exercem as garantias fundamentais bem como uma breve evolução histórica da ciência processual na busca por uma definição de processo se fazem necessárias, pois, a partir daí, verificar-se-á a relevância da existência de mecanismos que, conjugados com o princípio democrático, se mostram indispensáveis ao adequado exercício da função jurisdicional. Defende-se a submissão das atividades do Poder Público aos limites apresentados pelo Processo Constitucional e a observância irrestrita ao discurso democrático consubstanciado no princípio do contraditório como base legitimadora de todo ato do Estado.

Palavras-Chave: Jurisprudência - Garantias Fundamentais - Discurso Democrático Processo Constitucional.

\begin{abstract}
This paper aims to present criticisms constitutionally founded about the mass application of judicial mechanism, by the courts, at drafting a provision. It also aims to demonstrate how this practice can harm the performance of the parties in the development of the legal proceedings, restricting the incidence of fundamental constitutional guarantees and hence the rights that these mechanisms are designed to
\end{abstract}


protect. Then an analysis of the role that fundamental guarantees play as well as a brief historical evolution about the procedural science development on the search for a process definition are necessary because, from there, it will check the relevance of the existence of mechanisms that coupled with the democratic principle, are indispensable to the appropriate exercise of the jurisdictional function. It argues the submission of the government's activities to the limits provided by the Constitutional Process and unrestricted compliance to the democratic speech embodied in the adversarial principle as the legitimating basis of every act of the State.

Keywords: Jurisprudence - Fundamental Guarantees - Democratic Speech Constitutional Process.

\section{INTRODUÇÃO}

O presente trabalho centraliza breves reflexões no âmbito do Direito Processual Constitucional e analisa o papel da aplicação mecânica da jurisprudência como violação às garantias processuais, que cuidam da efetivação dos direitos fundamentais ${ }^{1}$.

Para tanto, introduziremos a ideia geral do conceito de jurisprudência bem como os limites de sua inserção no ordenamento jurídico como uma das fontes de criação do direito, acentuando os aspectos válidos dessa prática quando não confrontada com os princípios basilares do sistema normativo regulado pelo Devido Processo Legal.

Uma análise do conceito de princípios se faz necessária em conjunto com os fundamentos dos princípios institutivos do processo, alçados ao nível de garantia constitucional, cuja observância vincula a todos os órgãos do Estado e, em especial, os órgãos judiciários e seus agentes, no exercício de suas funções públicas.

Em seguida, verificam-se os impactos da jurisprudencialização confrontada com o papel legitimador das garantias processuais no decorrer da preparação do ato decisório

\footnotetext{
${ }^{1}$ Direitos fundamentais, em conceito sucinto, são as bases do Direito ou as garantias de proteção definidos pela Constituição, originados, principalmente, de reivindicações geradas a partir de situações de verdadeiro flagelo humano, como aquele verificado na Segunda Guerra Mundial. Vale aqui constar que o pós Segunda Guerra Mundial, com o seu resultado humano desastroso, necessariamente e por óbvio, impulsionou a reconstrução do Direito. Referido cenário de calamidade representou, por sua vez, a gênese do Estado Democrático de Direito.
} 
do juiz ou do órgão jurisdicional. A desmistificação da aparente harmonia entre padronização decisória e segurança jurídica é a principal consequência extraída entre aplicação da jurisprudência e adequado desenvolvimento do processo. Esta constatação apresenta contornos mais nítidos quando estamos diante de demandas judiciais a princípio semelhantes e, no entanto, eventualmente, podem surpreender o aplicador do direito as particularidades que incidem no caso concreto.

Diante desta situação, a jurisprudencialização implicaria em verdadeira agressão aos princípios do contraditório, ampla defesa, isonomia e fundamentação das decisões, uma vez que poderia desconsiderar as provas e os argumentos apresentados pelas partes, em discordância com o Devido Processo Legal, e oferecer uma prestação da atividade jurisdicional ilegítima e, portanto, inválida.

A partir desta afirmação, traçamos os principais pontos a respeito do elemento legitimador das decisões judiciais, a saber, o discurso democrático viabilizado no espaço dialógico procedimental. Passamos, então, à verificação do conceito das difundidas expressões paradigma e Estado Democrático de Direito, bem como as implicações derivadas da adoção deste sistema e que incidem na atuação dos poderes públicos.

Por meio de um breve escorço histórico das teorias do processo que integraram a ciência jurídica, observamos o papel desempenhado pelo juiz (ou tribunal) quando da prestação jurisdicional até alcançarmos os contornos atuais da ciência processual.

Finalizamos demonstrando que o discurso democrático é o fator legitimador de todo ato de poder do Estado porque direciona e limita a atuação dos agentes públicos, vinculando-os ao princípio democrático, cuja efetivação máxima se consubstancia na figura do processo de acordo com os ditames constitucionais do Devido Processo Legal.

\section{A JURISPRUDÊNCIA COMO FONTE DO DIREITO}

É cediço que o Direito, enquanto ciência social reguladora de fatos e condutas mediante a apresentação de proposições normativas, constrói e transforma o espaço e o tempo onde é desenvolvido e, paralelamente, remodela a si mesmo no âmbito de um lugar, época e valores sociais definidos. 
A teoria das fontes do direito, entendidas estas como o nascedouro das normas jurídicas, surgiu, modernamente, ao lado do desenvolvimento do capitalismo e do Estado burocrático, momento no qual se passou a exigir maior firmeza e segurança jurídica na transformação das normas costumeiras em leis efetivamente promulgadas. (FERRAZ JÚNIOR, 2010, p. 192).

Assim sendo, são fontes do direito todo ato ou fato que dê ensejo à criação jurídica, isto é, todo instrumento ou mecanismo que possibilite a edição de novos dispositivos normativos que passarão a integrar o sistema estrutural do ordenamento jurídico, como as leis (em sentido técnico), o costume, os princípios gerais de direito e a jurisprudência, esta última objeto principal deste trabalho.

Por definição, jurisprudência é meio de que se vale o juiz para dizer o direito (juris dictio), isto é, revelá-lo, transportá-lo da norma abstrata ao caso concreto, e que deriva de um considerável número de decisões dos tribunais no mesmo sentido. (REALE, 2010, p.167). Em suma, é a interpretação ${ }^{2}$ dada pelos tribunais, na figura de seus juízes e ministros, quando da apreciação da lide e que demanda certa consolidação deste entendimento frente aos demais casos semelhantes.

Dentre as fontes do direito consideradas no sistema jurídico do civil law ${ }^{3}$, ao qual o Brasil se adéqua, a jurisprudência é concebida como secundária ou acessória, tendo em vista o maior grau de subjetivismo presente na sua formação, diferente do que ocorre com a elaboração de leis pelo Legislativo, por exemplo. A despeito disso, é instrumento válido e eficaz na formação do provimento jurisdicional. (FERRAZ JUNIOR, 2010, p. 211).

No entanto, o que este trabalho visa indicar é a atual prática reiterada dos tribunais brasileiros no sentido de utilizarem este mecanismo como fonte primeira do Direito, abstendo-se de aplicarem o ordenamento jurídico e impedindo que os argumentos apresentados pelas partes no processo possam influir no provimento jurisdicional, sob o pretexto de que tal procedimento reforça a segurança jurídica que um órgão judiciário deve oferecer aos seus destinatários.

\footnotetext{
${ }^{2}$ No Estado Democrático de Direito, hermenêutica é o termo mais acertado a ser utilizado no que diz respeito à tarefa interpretativa. Isto porque ele amplia o sentido mecânico do termo interpretação. A respeito do tema, recomenda-se leitura do capítulo 5 da obra Teoria da Constituição, de autoria do professor José Emílio Medauar Ommati.

${ }^{3}$ Em diversos países de tradição romano-germânica, o direito é organizado em códigos, cujos exemplos principais são os códigos civis francês e alemão (Code Civil e Bürgerliches Gesetzbuch, respectivamente). É, portanto, típico deste sistema Civil Law o caráter escrito do direito. Outra característica dos direitos de tradição romano-germânica é a generalidade das normas jurídicas, que são aplicadas pelos juízes aos casos concretos.
} 
Como referido acima, não nos parece que o uso da jurisprudência traga prejuízos à ordem normativa brasileira, mesmo porque é fonte consolidada do direito, isto é, aplicada pelos mais diversos sistema jurídicos no mundo. Porém, o que se tem observado é uma tentativa frustrada dos órgãos do Judiciário brasileiro de introduzirem, às avessas, pois que completamente sem técnica, o sistema do Common Law no país. (FARIA, 2012, p. 89).

De origem anglo-americana, a tradição do Common Law ${ }^{4}$ privilegia os usos e costumes, consubstanciados nos chamados cases (ou precedentes) em detrimento do trabalho dos Parlamentos, de importância inferior. Tal prática, complexa e que possui vários outros mecanismos para sua adequada instalação, importada pelo Brasil, tem se mostrado violadora de inúmeras garantias constitucionalmente asseguradas para o devido andamento do processo.

Não obstante, a aplicação da jurisprudência como fonte primária tem dificultado o surgimento de novas teorias sobre matérias tidas como já consolidadas pelos tribunais, o que inviabiliza não só o desenvolvimento dos argumentos defendidos pelas partes no processo como congela todo o entendimento então dominante, sem que este possa ser refutado, aperfeiçoado, questionado ou ainda superado.

\section{JURISPRUDENCIALIZAÇÃO E VIOLAÇÃO DE GARANTIAS FUNDAMENTAIS}

Como visto supra, a jurisprudência é instrumento auxiliador na construção das normas individuais destinadas à solução do caso concreto, derivadas da interpretação das proposições abstratas elaboradas pelo poder legiferante. Analisar-se-á, entretanto, neste tópico, as consequências relativas às garantias processuais constitucionais provenientes do uso descurado dessa fonte do Direito, provando como esta prática viola

\footnotetext{
${ }^{4}$ Common law (do inglês "direito comum") é o direito que se desenvolveu em certos países por meio das decisões dos tribunais, e não mediante atos legislativos ou executivos. Nos sistemas de common law, o direito é criado ou aperfeiçoado pelos juízes: uma decisão a ser tomada num caso depende das decisões adotadas para casos anteriores e afeta o direito a ser aplicado a casos futuros. Nesse sistema, quando não existe um precedente, os juízes possuem a autoridade para criar o direito, estabelecendo um precedente.O conjunto de precedentes é chamado de Common Law e vincula todas as decisões futuras. O stare decisis, o princípio de que os casos semelhantes devem ser decididos conforme as mesmas regras, está no cerne de todos os sistemas de common law.
} 
mecanismos de execução e proteção de direitos e liberdades assegurados pela Constituição como limites ao poder das autoridades investidas nas funções estatais.

Em breve conceituação, princípios são enunciados genéricos extraídos do ordenamento jurídico e voltados finalisticamente para este, com força imperativa tal qual as normas jurídicas (regras jurídicas), tendo em vista sua função interpretativa, organizativa, diretiva e informativa do Direito. (DIAS, 2010, p. 103).

No sistema jurídico brasileiro, os princípios institutivos do processo, que originam e alicerçam o procedimento, tirando-o da órbita de mero rito formal e transformando-o em processo legitimamente considerado, estão consubstanciados no contraditório, na ampla defesa e na isonomia, e, como característico do Estado Democrático de Direito, são constitucionalmente assegurados às partes que integram a lide em busca de um provimento, seja ele administrativo ou judicial. (MADEIRA, 2012, p. 129).

Referidos princípios são entendidos ainda como proteção aos direitos fundamentais, isto é, são garantias de liberdade e outros direitos em face de arbitrariedades dentro do processo, valor máximo do direito porque diretamente vinculado à pessoa humana na persecução de suas prerrogativas legalmente previstas. São, portanto, garantias fundamentais constitucionalizadas que, ao lado de outros institutos, compõem o devido processo legal.

As garantias objetivam efetivar o alcance e aplicação dos direitos fundamentais, permitindo que estes se vejam concretizados não apenas formalmente na ordem jurídica, mas que exerçam seu objetivo último, isto é, que possibilitem aos cidadãos, seus destinatários, o pleno exercício de suas liberdades. (BARACHO, 2008, p. 54).

O reconhecimento de direitos fundamentais por meio da sua simples positivação nos textos legais não confere aos cidadãos a segurança de concretização destes, a qual se efetiva no meio jurisdicional através dos mecanismos processuais que ampliam e possibilitam a realização das liberdades essenciais quando as partes confrontam suas pretensões com vistas a uma sentença favorável ao seu direito, à sua posição na lide. Não obstante, o fenômeno de recepção dos direitos fundamentais pelas constituições contemporâneas obriga a observância da aplicação destes pelos três poderes, aplicação esta que só se dá pelo correto manejo das garantias fundamentais no momento de criação da proposição jurídica, na sua adequação ao caso concreto e também durante a sua fiscalização.

Nesse sentido, a lição de José Alfredo de Oliveira Baracho: 
Todos os direitos necessitam de garantias processuais para a sua efetiva concretização, sendo que algumas delas são sumárias. As garantias necessitam de proteção prática, concreta ou efetiva, para que não fiquem apenas como afirmações teóricas ou abstratas. As garantias constitucionais e processuais são criadas para amparo e proteção de direitos constitucionais afetados por leis, atos do Executivo ou decisões judiciais. As ações judiciais dão eficácia prática aos direitos proclamados e garantidos. Com o surgimento dos instrumentos processuais, os direitos constitucionais passaram a ter melhores mecanismos de defesa e efetivação. (BARACHO, 2008, p. 472).

Sem a pretensão de exaurir o tema, a doutrina tradicional esclarece os princípios institutivos do processo, o contraditório, a ampla defesa e a isonomia como, respectivamente, a participação dialética dos sujeitos e partes componentes da lide, a possibilidade de se valerem de todos os meios processuais legalmente assegurados para a apresentação de suas razões e o tratamento sob bases igualitárias, no sentido de se oportunizar o conhecimento de todos os procedimentos a serem realizados, bem como os mesmos prazos para que se manifestem no processo ${ }^{5}$. (MESQUITA, 2001, p. 134).

Referidos institutos, em conjunto com outros constitucionalmente previstos, compõem a essência do Devido Processo Constitucional, mecanismo próprio de um Estado Democrático de Direito, que confere aos seus cidadãos o exercício de proteção e efetivação de seus direitos em sede jurisdicional. (DUTRA, 2008, p. 28).

Assim, se na construção da sentença que ditará o alcance das pretensões das partes ou mesmo em fase anterior no decorrer do processo eventualmente descuida-se de algum princípio da Jurisdição Constitucional, o provimento resultante em nada se adéqua ao conceito de Processo, pois este pressupõe a presença ilimitada do contraditório, ampla defesa e isonomia. Diante desta situação o que se verifica são meros atos procedimentais mecanizados, porque desprovidos de sua razão fundamental, a saber, proporcionar às partes processuais o uso irrestrito das garantias constitucionais para que defendam seus direitos de forma ampla e digna.

$\mathrm{O}$ desrespeito a tais garantias quando do uso inconsciente e massificado da jurisprudência, objeto deste estudo, enseja justamente a descaracterização do processo,

\footnotetext{
${ }^{5}$ Nesse sentido, conferir também a obra do epistemólogo mineiro Rosemiro Pereira Leal, Teoria geral do processo: primeiros estudos.
} 
pois esta prática inibe a participação dos sujeitos no diálogo procedimentalizado através da imposição de teses construídas verticalmente pelos tribunais brasileiros.

A violação ao contraditório se verifica no instante em que o agente público investido na função jurisdicional, seja na figura do juiz ou do tribunal, simplesmente desconsidera os argumentos apresentados pela parte e fundamenta sua decisão nas interpretações tidas como oficiais no meio jurídico em relação à matéria apreciada. Consequentemente, a isonomia também é afetada, pois os meios e condições assegurados à parte para a apresentação de sua versão dos fatos não serão avaliados no momento da decisão judicial.

A jurisprudencialização do Direito, expressão indicativa da aplicação reiterada da jurisprudência dominante nas demandas levadas à apreciação dos juízes e tribunais brasileiros como mecanismo para fundamentação de suas decisões, é prática que decorre da chamada padronização decisória, em que órgãos jurisdicionais de hierarquia superior estabelecem entendimento consolidado em face do julgamento de inúmeros casos semelhantes e vinculam as demais instâncias para que apliquem a tese construída quando diante de situações análogas. Em suma, é uma tentativa de uniformização da jurisprudência, a qual apresenta um padrão de julgamento que, a princípio, pode se adequar à demanda apreciada pelo decisor, mas quando analisada detidamente, não alcança as especificidades do caso concreto. (THEODORO JUNIOR; NUNES; BAHIA, 2010, p. 24).

A tentativa de se criar standards para a solução das controvérsias em sede jurisdicional sob o preceito de que com isto se busca segurança jurídica é, ao contrário, evidente rejeição às garantias fundamentais inerentes à instalação e aplicação de um processo que realmente objetive a máxima efetivação de um ambiente discursivo que possibilite às partes sua participação dialógica irrestrita. A supressão deste cenário de dialogicidade enseja limitação ao contraditório e culmina na construção de um provimento ilegítimo para o qual não contribuíram os argumentos e provas apresentados pelas partes porque simplesmente desconsiderados pelo órgão decisor e substituídos por teses repetidamente ditadas em casos semelhantes. (FARIA, 2012, p. 49).

Juristas adeptos da padronização decisória defendem-na sob a justificativa de que o conhecimento antecipado dos cidadãos acerca da solução adotada pelos tribunais sobre sua controvérsia oferece segurança jurídica e não surpreende as partes processuais com mudanças nos julgamentos ou frequentes divergências interpretativas. No entanto, estes mesmos juristas parecem desconsiderar que o conceito de segurança jurídica 
relaciona-se mais com a certeza das partes de que suas ideias influirão na decisão judicial de forma racional e fundamentada, afastando-se da imposição de entendimentos tidos como oficiais e imunes ao questionamento, do que com a previsão de qual será o caminho escolhido pelo juiz no ato final do processo.

Outra justificativa que também deve ser repelida é a que se funda no tratamento igualitário que merecem as partes diante de demandas semelhantes, ou seja, decisões iguais para casos iguais. Porém, não parece haver tratamento isonômico quando as peculiaridades que tornam cada caso concretamente singular são mascaradas pelo uso mecanizado de padrões jurisprudenciais que, formalmente, funcionam como argumentos persuasivos, mas materialmente objetivam a vinculação de todos os órgãos e instâncias jurídicas. (THEODORO JUNIOR; NUNES; BAHIA, 2010, p. 25).

A homogeneidade no resultado da prestação da atividade jurisdicional na busca incessante por julgamentos mais rápidos e decisões céleres não somente mitiga a função das garantias fundamentais como mecanismos de limitação do poder estatal como encaminha o desenvolvimento do espaço processual argumentativo para um congelamento da ciência jurídica, impedindo assim que novas teses surjam para sobrepor aquelas já consolidadamente pronunciadas pelos órgãos judiciais. A consequência é a impossibilidade de que novos juristas construam e apresentem teorias inéditas e concorrentes que trariam a renovação de padrões decisórios em muitos casos onde fosse pertinente. (FARIA, 2012, p. 102).

\section{DISCURSO DEMOCRÁTICO E LEGITIMIDADE DECISÓRIA}

Este último tópico objetiva abordar a função dos princípios processuais constitucionais, sob os pressupostos do Estado Democrático de Direito, na formação de decisões que se apresentem como legítimos provimentos construídos pela comunidade jurídica num ambiente procedimental dialético de efetivação de direitos e garantias fundamentais.

Constantemente, a comunidade jurídica invoca os termos paradigma e Estado Democrático de Direito, embora em sua maioria os autores não tracem o real significado destas expressões. Felizmente, Ronaldo Brêtas (2010) esclarece, sob as bases da doutrina alemã, que, separando-se Estado de Direito e Estado Democrático, este último 
pode ser definido como um regime estatal característico da modernidade, segundo o qual se delineiam as regras regulamentadoras das atividades das autoridades públicas, ao mesmo tempo em que se limitam estas funções por meio de mecanismos, assegurados legalmente, capazes de proteger os cidadãos na persecução de seus direitos fundamentais e inibir qualquer atuação arbitrária por parte dos agentes públicos, tudo se passando sob o fundamento do império da lei.

Explica ainda o citado jurista que o Estado Democrático, alçado à condição de princípio em virtude do surgimento do constitucionalismo, está atrelado ao exercício do poder pelo povo, à legitimação de todos os atos e funções do Estado pela participação e fiscalização irrestrita daquela que deve ser a criadora e destinatária das normas jurídicas, a comunidade jurídica. (DIAS, 2010, p. 60).

Partindo agora para a análise do termo paradigma, continua a doutrina de Ronaldo Brêtas (2010) no sentido de definir esta expressão como um conjunto de normas, princípios e elementos estruturantes de um sistema que funcionará como base para os estudos de uma Teoria do Estado, distintamente de outros autores que preferem determinar o paradigma como um modelo, um padrão de Estado a ser seguido.

Tal significação não se mostra adequada, pois o paradigma do Estado Democrático de Direito, adotado pela Constituição brasileira de 1988, não deve ser visto apenas como uma referência, mas como verdadeiro complexo jurídico-normativo capaz de balizar toda a estrutura de um Estado, sendo que referido balizamento é viabilizado através do processo, que representa uma instituição constitucionalizada destinada a oferecer a qualquer cidadão a oportunidade de defender e efetivar seus direitos, questionar atos da gestão pública e das autoridades competentes, e é influenciado diretamente pelo paradigma estatal vigente em determinada época e lugar. (SOUSA, 2009, p. 30).

Em breve digressão histórica, o Estado Liberal foi o proclamador dos chamados direitos negativos e concebia o ordenamento jurídico como um compêndio de normas criadas finalisticamente para a proteção das liberdades declaradas fundamentais ao indivíduo, especialmente no que se referia à propriedade privada. Limitar a atuação do Estado e impedir que este ultrapasse a esfera da vida privada dos cidadãos, preceitos próprios do Liberalismo, refletiu resultados diretamente nas funções desempenhadas pelos agentes públicos. A atividade jurisdicional se restringiu a declarar a existência ou não das liberdades negativas no caso concreto sem atentar para a efetivação de outros direitos inerentes à condição humana e para as discordâncias havidas entre as classes 
sociais, fatores obscurecidos pelo acelerado desenvolvimento do capitalismo. (LEAL, 2002, p. 26).

$\mathrm{Na}$ tentativa de corrigir as falhas daquele sistema, a implementação do Estado Social permitiu o surgimento dos direitos de caráter positivo, isto é, direitos não apenas formalmente assegurados nos textos legais, mas efetivamente garantidos pela atividade estatal através de políticas públicas e programas sociais. Nesse sentido, caberia à função jurisdicional materializar a justiça a qualquer custo para a solução das demandas da sociedade, com vistas principalmente a diminuir os desequilíbrios das classes sociais, ainda que para isto o juiz, ou o órgão julgador, tivesse de considerar seu próprio conceito de justiça em detrimento das disposições normativas. (LEAL, 2008, p. 28).

O Estado Democrático de Direito se apresenta como a resposta ideal às lacunas e insuficiências de seus antecessores, visto que objetiva solucionar o problema da legitimidade das funções estatais (função jurisdicional, administrativa e legislativa) entregando ao povo, a comunidade jurídica e razão fundamental do próprio Estado, o poder de criar, alterar, fiscalizar e questionar todo o ordenamento jurídico-político a que estão submetidos. O povo é, assim, o agente legitimador do Direito, e o faz especialmente através do Processo, instituição que proporciona ao cidadão o direito de discutir acerca de todo e qualquer assunto atinente à sua vida e à vida em sociedade, transformando os atos e decisões do Estado em verdadeira síntese correspondente ao debate proferido pelos seus destinatários mesmos.

Entretanto, vale destacar, foi necessária uma grande evolução na ciência do direito processual para se alcançar este pensamento, havendo ainda juristas ferrenhamente atrelados a teorias que claramente não mais se adéquam ao atual estágio em que se encontram as sociedades contemporâneas marcadas pelo princípio da democracia, especialmente aqueles que ainda definem o Processo como um instrumento a serviço da jurisdição.

Este pensamento remonta à essência da teoria da relação jurídica de Bülow, a qual entendia o Processo como uma relação que envolvia autor, réu e juiz, estabelecida conforme graus de subordinação em que este último exercia o papel de protagonista, estando livre para ignorar provas e fatos alegados pelas partes no momento de elaborar a sua decisão (BÜLOW, 2005).

Construindo sua própria teoria, Fazzalari rechaça a ideia de sujeição entre as partes e constrói novos conceitos de processo e procedimento (processo é espécie do gênero procedimento), este último unido ao contraditório (FAZZALARI, 1992). 
Posteriormente, Andolina e Vignera reproduzem a teoria do processo como procedimento em contraditório, porém adicionam reflexos de uma aproximação entre processo e Constituição (ANDOLINA, VIGENRA, 1997). A teoria constitucionalista do processo ergue o contraditório à condição de princípio, cuja observância é obrigatória em todos os atos preparatórios do provimento jurisdicional.

A teoria neo-institucionalista, desenvolvida por Rosemiro Pereira Leal, reescreve a teoria constitucionalista sob as bases do Estado Democrático de Direito, definindo o processo como instituição constitucionalizada e legitimadora das decisões judiciais, o que somente é permitido pela observância obrigatória dos princípios constitucionais balizadores da ordem processual, dentre os quais o contraditório, a ampla defesa e a isonomia adquirem a característica de direito-garantia, porque capazes de assegurar aos legitimados do direito de ação um ambiente dialético, e não meramente retórico, para a apresentação de suas razões na busca por um provimento jurisdicional. (LEAL, 2012, p. 90).

Sendo assim, o ambiente argumentativo processual, propiciado pela observância irrestrita dos princípios constitucionais, em especial o contraditório, é o fator legitimador das decisões judiciais, porque vincula a sentença ao que foi debatido pelas partes no processo, e somente. Num Estado Democrático de Direito, no qual todo ato de poder deve ser exercido pelo povo, destinatário destes mesmos atos, e estar em conformidade com a legislação vigente, não se pode aceitar que a jurisdição seja exercida por um juiz que conduza o processo unilateralmente, aplicando suas convicções e sujeitando as partes a um provimento para o qual estes não contribuíram. Em casos tais, a decisão não é legítima e nem o pode ser, porque, se a comunidade jurídica, fonte de todo poder, não participou da formação do provimento, pode-se dizer que este não é mais que uma imposição do Estado, o que não é cabível no atual paradigma constitucional.

Nesse sentido, a afirmação de Dhenis Cruz Madeira:

No Direito Democrático, o provimento não advém de uma atividade solitária de uma autoridade, eis que todo poder emana do povo e, justamente por isso, a garantia de fiscalização popular não pode ser suplantada sem prejuízo da legitimidade democrática. (MADEIRA, 2012, P. 40). 
A figura do juiz solipsista, conhecedor de todos os males que afligem a sociedade e o único capaz de distribuir justiça aos que a procuram, porque assim determinou o Estado no exercício de sua soberania interna, deve ser afastada da perspectiva contemporânea das funções estatais, no sentido de permitir que o princípio democrático seja materialmente aplicado ao âmbito processual e deixe de ser mero dispositivo normativo formal, que mascara um Judiciário cujos agentes priorizam suas próprias razões e entendimentos quando incumbidos na função de solucionar as lides que lhes são apresentadas.

O ideal é que o julgador conduza o processo observando as regras procedimentais, mas oportunize às partes um espaço processual argumentativo, no qual estas possam debater e apresentar todas as provas e documentos que considerem relevantes para o atendimento de sua pretensão, em simétrica paridade, ao passo que na formulação do ato final do processo aquele mesmo julgador tenha como limites os fatos e fundamentos alegados. Ao final o que se tem não é uma decisão tomada pelo juiz, mas um provimento jurisdicional, que visa à melhor solução possível do caso concreto, construído pelas partes processuais dialogicamente e em plena concordância com os princípios constitucionais do devido processo.

O processo, portanto, não deve ser entendido, como querem inúmeros juristas brasileiros, como uma relação jurídica na qual os sujeitos que a compõem exercem posições de subordinação uns em face dos outros, isto é, o réu não deve ser visto como subordinado à pretensão do autor, tampouco este considerado subordinado ao Estadojuiz. Da teoria instrumentalista não germinam os efeitos desejados de uma prestação jurisdicional num Estado que tem por modelo a Teoria da Democracia e a Teoria do Direito. Admitir que as partes no processo figurem em posições de superioridade e inferioridade é negar os avanços obtidos pela Teoria do Processo, na construção de princípios constitucionalizados, e sua perfeita adequabilidade ao Estado Democrático de Direito, pelas razões já expostas. (VARGAS, 2012, p. 130).

A legitimidade dos atos e decisões que toma o Estado só se verifica quando o povo (ou comunidade jurídica) participa fiscalizando, aprovando, modificando e até mesmo rejeitando as determinações das autoridades públicas. É o discurso democrático, assim, fator legitimador de tudo quanto diz respeito à atividade estatal, seja no âmbito administrativo, legislativo ou judicial, porque vincula estas funções à observância direta dos princípios constitucionais historicamente conquistados, permitindo com que os 
destinatários das normas exerçam o papel também de seu principal construtor e intérprete.

\section{CONSIDERAÇÕES FINAIS}

A evolução da ciência jurídica, em especial o ramo do Direito Processual, caminha historicamente ao lado das conquistas sociais alcançadas pelas mais variadas nações ao redor do mundo. Isto porque um ordenamento jurídico deve representar formal e sistematicamente aquilo que impulsiona as pretensões de um povo, o espírito da comunidade jurídica. Neste sentido, o desenvolvimento de uma Teoria do Processo consolidada constitucionalmente surge para assegurar aos cidadãos que as normas de direito substancial (ou material) legislativamente criadas possam efetivamente ser aplicadas pelo Estado com a segurança que as garantias processuais imprimem ao procedimento judicial.

Dentro dessa perspectiva, o uso massificado da jurisprudência, fonte formal do Direito cuja aplicação, no sistema jurídico brasileiro de raízes romano-germânicas, possui relevância prática e acadêmica cada vez mais aparentes, certamente implica na supressão ou, quando muito, na mitigação do princípio norteador de toda criação normativa: o Devido Processo Legal.

A não observância das garantias constitucionais ao longo do desenvolvimento do procedimento para a construção do provimento final e na elaboração dos fundamentos que servirão de base argumentativa para a sentença enseja a ilegitimidade do ato decisório. A supressão do princípio constitucional do contraditório, sustentáculo de um Estado Democrático, se mostra evidente nas tentativas dos Poderes Legislativo e Judiciário de implantarem o fenômeno da padronização decisória com vistas ao alcance de uma segurança jurídica plena.

Descuida-se, porém, da participação dos sujeitos processuais na formação de um ato decisório que incidirá na sua esfera de interesses e ditará a viabilidade ou não de suas pretensões deduzidas (ou resistidas) em juízo. E, nestas circunstâncias, o princípio democrático, legitimador de todo ato de poder derivado de uma autoridade estatal, consubstanciado no espaço dialógico que somente o Processo Constitucional pode 
oferecer às partes, desaparece e dá lugar a uma sequencia de atos procedimentais que culminam com a imposição de uma sentença para a qual as partes não contribuíram.

A aplicação da jurisprudência como elemento auxiliador na persecução da construção do ato decisório é válida e deve ser sempre incentivada. Contudo, as ressalvas aqui analisadas, e que levam em consideração os efeitos limitadores da atuação das garantias constitucionais que tal prática pode propiciar, precisam ser observadas quando as autoridades judiciais se prestarem a fundamentar seus atos em entendimentos jurisprudenciais consagrados. A única forma de devolver aos jurisdicionados uma prestação do Estado legítima é garantindo que os mesmos possam discutir o mérito de suas pretensões de maneira ampla e justa, fazendo com que os argumentos e provas apresentados ao longo do processo atuem como balizador do provimento final.

\section{REFERÊNCIAS}

ANDOLINA, Italo; VIGNERA, Giuseppe. I fondamenti constituzionali della giustizia civile: il modello constituzionale Del processo civile italiano. 2. ed. Torino: G. Giappichelli Editore, 1997.

BARACHO, José Alfredo de Oliveira. Direito processual constitucional: aspectos contemporâneos. Belo Horizonte: Fórum, 2008.

BÜLOW, Oskar von. Teoria das exceções e dos pressupostos processuais. Campinas: LZN, 2005.

CARVALHO NETTO; Menelick de.; SCOTTI, Guilherme. Os direitos fundamentais e a(in)certeza do direito: a produtividade das tensões principiológicas e a superação do sistema de regras.Belo Horizonte: Fórum, 2011.

CASTRO, João Antônio Lima (Coord.). Direito processual: aspectos contemporâneos do direito processual. Belo Horizonte: PUC Minas, Instituto de Educação Continuada, 2008 . 
DIAS, Ronaldo Brêtas de Carvalho. Processo constitucional e estado democrático de direito. Belo Horizonte: Del Rey, 2010.

FARIA, Gustavo de Castro. Jurisprudencialização do direito e legitimidade decisória no processo civil brasileiro. 2012. 165f. Dissertação (Mestrado) - Pontifícia Universidade Católica de Minas Gerais, Programa de Pós-Graduação em Direito.

FAZZALARI, Elio. Istituzioni di diritto processuale. Padova, Cedam, 1992.

FERRAZ JÚNIOR, Tércio Sampaio. Introdução ao estudo do Direito. São Paulo: Atlas, 2010.

FILHO, Ruy Alves Henriques. Direitos fundamentais e processo. Rio de Janeiro: Renovar, 2008.

LEAL, André Cordeiro. $\mathbf{O}$ contraditório e a fundamentação das decisões: no direito processual democrático. Belo Horizonte: Mandamentos, 2002. 111 p.

LEAL, Rosemiro Pereira. Teoria geral do processo: primeiros estudos. 10. ed. rev. e aum. São Paulo: Forense, 2011.

LEAL, Rosemiro Pereira. Súmulas vinculantes: sua ilegitimidade no Estado Democrático de Direito. Revista da Faculdade Mineira de Direito, Belo Horizonte, v.8, n.16, p. 162-198, $2^{\circ}$ sem. 2005.

MADEIRA, Dhenis Cruz. Processo de conhecimento e cognição: uma inserção no estado democrático de direito. Curitiba: Juruá, 2012.

MAGALHÃES, Joseli Lima (Coord.). Temas de direito processual democrático. Teresina: EDUFPI, 2012.

MESQUITA, Gil Ferreira de. Princípios do contraditório e da ampla defesa no processo civil brasileiro. São Paulo: Editora Juarez de Oliveira, 2003. 
OMMATI, José Emílio Medauar. Teoria da Constituição, 2a edição, RJ: Lumen Juris, 2013.

REALE, Miguel. Lições preliminares de Direito. São Paulo: Saraiva, 2010.

SANTOS, Evaristo Aragão. Sobre a importância e os riscos que corre hoje a criatividade jurisprudencial. Revista de Processo, São Paulo, v.35, n.181, p.38-58, mar. 2010 .

SOUSA, Kelen Cristina Fonseca de. O princípio do contraditório: uma reconstrução sob a ótica do paradigma do Estado democrático de direito. 2009. 132f. Dissertação (Mestrado) - Pontifícia Universidade Católica de Minas Gerais, Programa de PósGraduação em Direito.

THEODORO JÚNIOR, Humberto; NUNES, Dierle José Coelho; BAHIA, Alexandre Gustavo Melo Franco. Breves considerações sobre a politização do Judiciário e sobre o panorama de aplicação no direito brasileiro: Análise da convergência entre o civil law e o common law e dos problemas da padronização decisória. Revista de Processo, São Paulo, v.35, n.189, p.09-52, nov. 2010.

THEODORO JÚNIOR, Humberto. Constituição e Processo: desafios constitucionais da reforma do Processo Civil no Brasil. In: MACHADO, Felipe Daniel Amorim e CATTONI DE OLIVEIRA. Marcelo Andrade (Coords.). Constituição e Processo: a contribuição do Processo ao constitucionalismo brasileiro. Belo Horizonte: Del Rey, 2009. 